\title{
EL PROYECTO PARA LA CAPILLA DE LA INQUISICION
}

\author{
POR \\ FRANCISCO DE LA MAZA
}

NUNCA había estado el tribunal del Santo Oficio de la Inquisición de México tan rico como a mediados del siglo xvir. Un inesperado suceso vino a enriquecer a los señores inquisidores de manera considerable: la sublevęción de los portugueses contra el trono español en el año de 1640. Recelosas las entonces fidelísimas colonias americanas de los "traidores", de los cuales habia muchos y casi todos de ascendencia judia, se dieron a vigilar a los portugueses por medio del Santo Oficio, descubriéndose en México una supuesta conjuración llamada la "complicidad grande", por la que fueron encarcelados más de doscientos judios lusitanos entre los años de 1642 y 1648 . Hubo cón ellos varios autos de fe, siendo el más famoso el de 1649, el "Auto Grande", en el que murió dramáticamente el célebre rabino Tomás Tremiño de Sobremonte y cuya descripción mereció los honores de la imprentạ.

Según don José Toribio Medina: "desde 1640 a 1646 habian entrado a la Inquisición 429,389 pesos y las confiscaciones hechas a los reos en 
1646 fueron de 38,700 pesos y las de 1647 a 148,560 pesos". En el "Auto Grande" las ganacias inquisitoriales fueron, tranquilamente, de 3.000,000 de pesos. ${ }^{1}$ Con todo este dinero se hicieron serias reparaciones al edificio de la Inquisición y hasta se pensó construir "nuevo tribunal en las casas deste Sancto Officio" en marzo de 1655, encomendando los planos al arquitecto Diego López Murillo. La obra se puso a remate, según costumbre de la época, ganándola Vicenzo Varrocio Escallola, conocido arquitecto italiano de la Catedral de Morelia. ${ }^{2}$ En 1657 se pensó también en hacer nuevas las cárceles secretas, haciendo los planos el arquitecto Diego de los Santos y Avila, maestro mayor de las obras del propio Santo Oficio, el cual calculó su proyecto en 37,700 pesos y ganando el remate Pedro Durán. Los planos fueron duramente criticados por los arquitectos Rodrigo Díaz de Aguilera y Rodrigo Bemal de Ortega, pero parece que se comenzaron las obras a fines del mismo año. ${ }^{a}$

Se quiso además fabricar la capilla particular del tribunal, por proposición de la cofradía de San Pedro Arbués, inquisidor mayor de Barcelona y "mártir" del Santo Oficio. El 3 de julio de 1659 los cofrades dirigieron a los inquisidores un memorial para que lo firmasen y enviasen al virrey duque de Alburquerque, en el que se decía que "los tribunales del Sancto Officio, como las Reales Chancillerias y Audiencias, han tenido siempre y tienen capillas a donde los Jueces y Ministros oien por comunidad misa antes de entrar en audiencias y los tribunales del Sancto Officio han tenido siempre y tienen maiores edificios de capillas porque en ellas deben tambien celebrar algunos autos particulares de fé y assi es general, o casi tal, tener capillas mui grandes con puertas a las calles . . y a determiniado la Cofradia del St $^{\circ} \mathbf{~ P e d r o ~ M a ́ r t i r ~ d e d i c a t ~ c a p i l l a ~ d e s e n t e ~}$ al santo a costa de la Cofradia, en el sitio en que era la sala del tribunal antiguo que corre desde la esquina principal a lo largo por la calle de la cárcel perpetua, quédando la puerta de dicha capilla en la principal que ai tiener las casa de esta Sancta Inquisisción".4

E1 11 de agosto se concedió la licencia, pero ya los inquisidores habían mandado hacer los planos a su arquitecto, Diego de los Santos y Avila, que presentó su proyecto el 14 de febrero. Por ser importante lo publico integro, respetando la ortografía original, ya que es autógrafo,

1 La Inquítición en México. Página 209.

2 Archivo General de la Nación. Real Fisco. Tomo 27, folio 110.

3 Arébivo General de la Nación. Ramo de Inquisición. Tomo 115, exp. 1.

4 Archivo Seneral de lin Nucion. Ramo de Inquisición. Tomo 584 , folio 89. 
salvo los acentos y la puntuación que no quitan su sabor barroco e ingenuo del viejo alarife inquisitorial y facilitan su lectura. Dice: "Diego de los Santos y Avila, maestro de las obras deste Sancto Ofissio, en cunplimiento del mandato de VSS (he) hecho la planta y trasa de la yglesia que VSS* quiere (n) hazer del $\mathbf{S}^{r} \mathbf{S}^{\mathbf{n}}$. Pedro mártir que a de fabricarse en la esquina mesma del Sancto Ofissio donde antes hera el tribunal biejo y las condisiones de dicha trasa son las siguientes: Primeramente ha de mirar la dicha yglesia de oriente a poniente, con una portada mui suntuosa de canteria y esta portada se a de poner donde oy está la entrada del Santo Ofisio y la que oy está se a de pasar más adelante, enfrente de la puerta de enmedio de dicho Santo Ofisio, de manera que el saguán quede quadrado, yten más, se a de desbaratar y deshazer todo lo edificado conformándose con el largo y ancho de dicha planta sin que se pueda aprovechar cosa ninguna del edifisio biejo por ser mut dévil y de mala calidad; y después de que esté todo desbaratado $y$ enrasado se ha de sanjear y avrir los simientos, que an de tener de ancho tres baras y de fondo dos baras y media; y a de tener de ancho la dicha yglesia onse baras y de largo quarenta baras $y$ seis estribos en cada lado, encadenados, que atraviesen por enmedio de la yglesin dichas cadenas de estribo a estribo, para que dicho edifisio quede mui fuerte $y$ no aga bisio ninguno y después que estén las sanjas habiertas con las calidades que tengo dichas se a de estacar mui fuertemente con estacas de sedro de a dos baras y tersia de largo y de estaca a estaca no a de aver más de una quarta y después que esté todo estacado se an de masisar todos los guecos de entre estaca a estaca con piedra menuda a punta de barreta hasta que empareje con las cabesas de las estacas y en estando en este estado el dicho edifsio se ande masisar los dichos simientos con mescla y piedra dura asta (la) superficie de la tierra y ula bara más lebantado del suclo. Iten más, sobre dichos simientos se a de montear nuestro edifisio formando las paredes maestras y estribos y medias muestras según como la planta lo demuestra, observando (que) las paredes maestras an de tener de grueso por lo bajo dos baras y media y tres de alto que es lo que a de tener de alto la yglesia baja o entierro de la cofradia, con sus bóbedas rrebasadas que estriben y caigan sobre unas medias muestras o pilastras de piedra dura labrada de Suchimilco, según como la planta lo demuestra, quedando por lo bajo en forma de dos nabes; y en cada lado de dicho entierro an de tener quatro bentanas con dos rrejas de fierro y cada bentana de bara y media en quadro una mas alta que la otra porque no se colunbre desde la calle lo que ubiere dentro y estas veritanas, las que cayeren a la calle y al patio, an de ser de esquinas de Suchimiloo 
de tesontli o piedra dura, por ser el material mas fuerte y que no le entra tequesquite; se a de rrebocar de pardo y blanquear y enlosar de tenayucas labradaś el suelo de dicho entierro y bruñirlo todo, que paresca un espejo, con sus poyos de un lado y otro, en rtedondo, de una bara de ancho y una bara de alto, enladiriliados dichos poyos y sus senefas de almagre y enmedio de dicho entierro se a de hazer una peana de altar de cal y canto que mire a dos bases del tamaño que conbiene para que a un tienpo se selebre misa sin que se estorben de una parte a otra. Iten más, se le a de dar la entrada deste entierro en el presbiterio del altar mayor $y$ an de ser dos entradas una al lado del evangelio y otra al lado de la epístola con sus escalones mui anchos de tenayucas labradas' y sus puertas de tablones de sedro con sus marcos de lo mismo para que se baje tan solamente quando VSS* mandare ( $n$ ), hechándoles a cada puerta sus serraduras y llave mui fuerte. Iten más, ensima desta fábrica que tengo espesificada se a de formar la iglesia, lebantando las paredes maestras y pilastras de cantería y estribos según como la planta lo demuestra, dándole de paredes maestras asta el tersio de su alto dos baras de grueso y desde el tersio asta el mobimiento de lo aito bara y dos tersias, que son la desminución que le corresponden con sus molduras y guarnisiones de canteria y pilastras y arcos que tanbien an de ser de canteria y las bentanas altas a ser todas de tesontli labrado y fingidas de canteria rrebocándolas de pardo y ensima el color de canteria. Las bóbedas que pertenesen en esta fábrica son lunetos, por ser las más ermosas y más fuertes, y le corresponden en las partes prolongadas, $y$ éstas se an de fabricar lebantadas de punto por la seguridad y permanensia, poniendo en esto el maestro que las fabricare todo el cuidado que fuere menester no fiándose de ofisiales asi en armar sus simbrias como en la fábrica de ellas que con estas calidades se conseguirá el fin que se pretende; y esta yglesia alta a de tener de alto asta el mobimiento del arco dies baras y cinco y media que lebanta el arco hasen quince $y$ media, $y$ media de grueso de arco y media del lebantado del punto que a de tener cada bóbeda que por todas hasen dies y seis baras y media, que es lo que a de tener de alto la dicha yglesia. Iten más, la media maranja a de ser rredonda, según como la planta lo demuestra, que lebanta cinco baras del cuerpo de la yglesia, formándola de la manera que se demuestra, con todas las guarnisiones que le pertenesen por dentro y fuera y su pirámide que le sirve de linterna que a de ser de tesontil labrado. Iten más, a toda esta fábrica por de dentro sea de enlusir y blanquear y dar de color a las canterias y listar las junturas de negro y blanco y brunir las paredes como un espejo y hechar sus senefas de asulejos fingidos de colores finos al olio, 
todo en rredondo de la yglesia, de una bara de alto. Iten más, se a de subir desde la calle con dies y seis escalones que se an de rrepartir de manera qu todos caygan a la calle rretirando hasia adentro el edifisio todo lo que ocuparen dichos escalones; y estos escalones an de ser de tenayucas mui gruesas labradas con su base. Iten más, toda la yglesia se a de entenayucar con tenayucas labradas y muy bien rrebocadas las junturas con mui buena mescla y el presbiterio se a de lebantar el suelo con sinco escalones labrados como todo lo demás, y enmedio del testero del presbiterio se a de haser la peana del altar mayor de cal y canto del tamaño que conviniere con un escalón en rredondo, donde pisen los sacerdotes que selebraren misa. Iten más, en la testera del altar mayor, a los dos lados del altar, se an de haser dos puertas de buen tamaño de tesontli para entrar a la sacristia, que se a de dejar en esta parte del tamaño que paresiere o diere lugar y esta sacristia a de ser forzosamente alta y baja, por lo que sube el entierro de la cofradia y se a de enmaderar con bigas de colegio de uyamel, al peso del presbiterio y enladrillar el suelo dándole una bentana a la calle con su rreja de fierro de lunbrera, que tenga de ancho vara y media y de alto dos baras y media con seis bentanas de madera clabadisa y las puertas también clabadisas de madera de sedro como la bentana, y a de tener de alto la sacristia alta quatro baras y se a de enmaderar con bigas de colegio de a dose baras de largo mui enlabradas y asepilladas con sus soleras de moldura y la tablasón de Suchimilco y se a de dar puerta por la parte de adentro por donde oy entra al tribunal el inquisidor don Juan Saes de Mañozca y se an de haser a dicha puerta sus pies derechos de tesontli y sus puertas de madera clabadisa; y (en) la piesa beja que le corresponde se ará otra puerta en el patio en derecho de la de arriba con su bentana a la calle hecha de funbrera de fierro del tamaño que paresiere. Iten más, esta yglesia a defener su coro de bóbeda segun como la planta lo demuestra y el suelo alto se a de enladrillar y hechar sus barandillas de sedro torneado con sus dos soleras mui anchas de sedro moldadas a dos ases; y a los lados del coro a de tener sus dos tribunas, una en cada lado, de selusías de bosel rredondas con sus postigos; que cada tribuna a de tener de largo quatro baras y de ancho bara media sobre canes de sedro torneado, digo mui bien moldadas, y su coronasión de talla de sedro con sus puertas en derecho de las barandillas del coro para que quede dividido del coro y no se lo comunique; y la entrada de este coro a de ser por el corredor del sehor inquisidor don Fran"o de Estrada y se dará otra subida y bajada para el coro en un rrincón como entramos de la calle por la yglesia a mano isquier- 
da, en forma de caracol, como la planta io demuestra, enbebida en el propio estribo dandole lo suficiente al estribo para que quepa el dicho caracol con sus escalones de tenayucas labradas y sus troneras para la lus, todos los qute fueren necesarios; y este caracol a de subir asta las asoteas de dicha yglesia a las dos torresillas que an de dar una en cada esquina para adorno de dicha fábrica; y a de tener sus puertas de madera clabadisas alta y baja en el dicho caracol, con sus serraduras y llaves. Iten más, lo último desta fábrica es la portada prinsipal que a de ser de orden jónica de dos cuerpos de canteria que el primero a de ser de dos pilastras, una en cada lado con sus pies derechos y pedestales, arquitrabes, frisos y cornisas y arcos, con sus enjutas y contramuros; y el segundo cuerpo a de tener su nicho con sus pilastras y motibos y contramuros y rresaltos $y$ frontispisios y escudos de armas $y$ rremates $y$ un $S^{r}$ San Pedro Mártir de vulto, de piedra blanca de villerias; $y$ todo esto se a de executar y labrar segun y conforme la planta de dicha portada de que hago demostrasión; y supuesto que dicha portada está en estampa y se an de governar con ella executándola en obra biba, sin que escrepe (discrepe) en cosa ninguna de lo que está dibujado: Iten más, las basas y pedestales de dicha portada an de ser de piedra de chiluca y asimesmo todas las basas de las pilastras dentro de la yglesia; y asimesmo se an de erladrillar las bóbedas y hechar sus canales de canteria con sus caños de plomo mui grandes, un canal en cada estribo; y despues del enladrillado de las bóbedas se a de hechar ormigón de tesontli y cal de arena, que tenga una pulgada porque no se pasen las aguas, y ese ormigón a de ser mui bruñido porque las aguas no se enbeban, sino que rresbalen. Iten más, los rremates de las bóbedas que le corresponden a cada estribo an de ser de ladrillo y tesontli y bien rrebocados. Iten más, toda la fachada de dicha fábrica a de quedar a piedra descubierta como la trasa lo demues tra, $\tan$ solamente a todas las canterias se le a de dar de color de cantería y listar las junturas de negro y blanco, assi a las esquinas de los estribos se an de fingir de sillares de canteria en todas las esquinas y listar sus junturas como todo lo demás. Iten más, las mesclas an de ser de sinco de arena $y$ dos de cal y para las bobedas uno de arena, como uno de cal y uno de tesontli y asiéndose como aqui lo digo se conseguirá el buen fin que se pretende. Iten más, las puertas de madera para la iglesia an de ser de sedro y nogal de tableros mui espesos, de manera que no quepa cabesa y mui bien moldados con escuadros y abrasaderas de fierro y sus postigos con sus piesas de fíerro y sus quisialeras de lo mesmo. Esto es lo que e alcansado segun mi corta capasidad y prometo a VSS que he hecho todas las dilgen- 


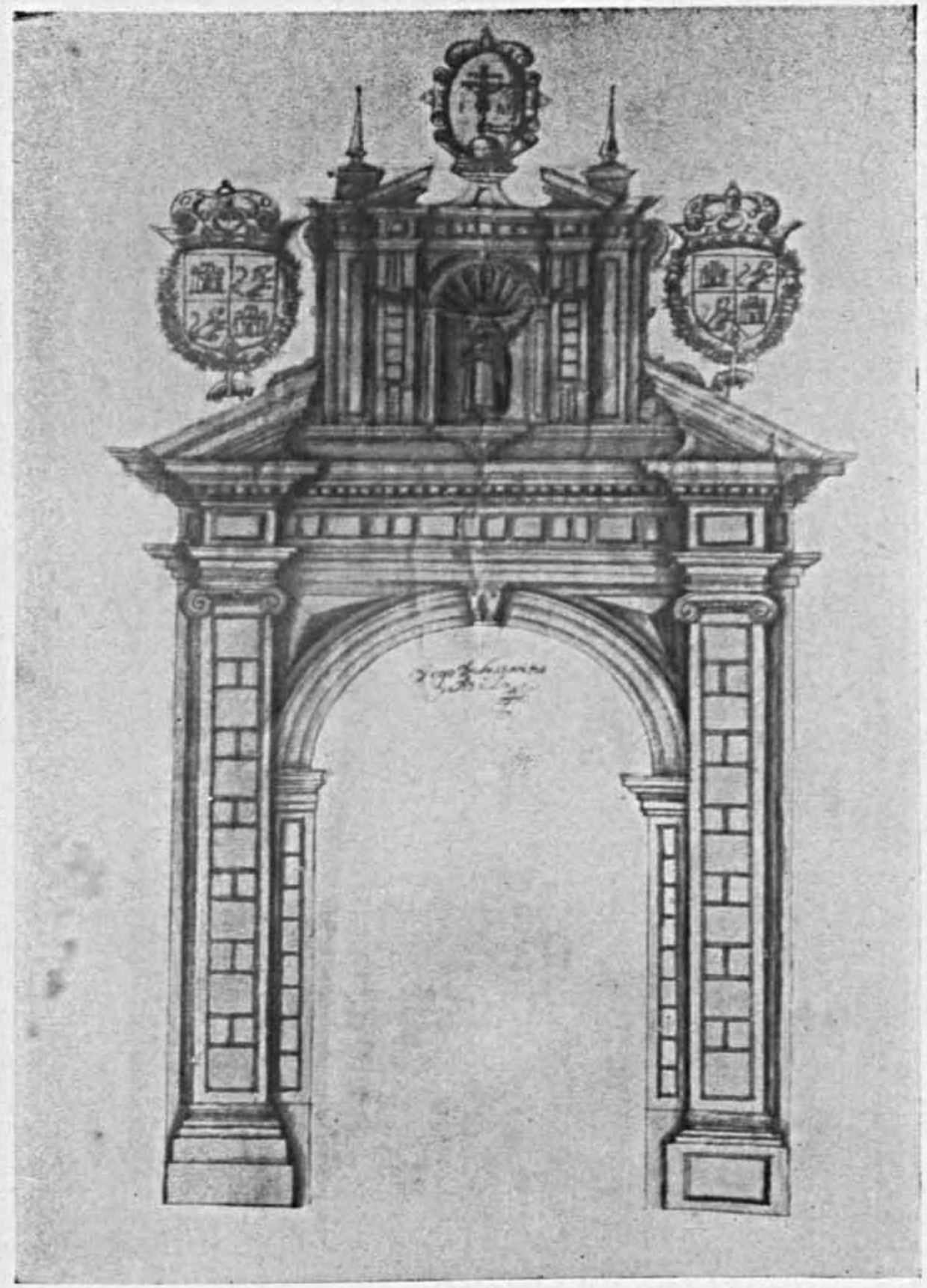

Fig. 1. Dibujo de la fachada principal en el proyecto para la capilla de la Inquisición. 
DOI: http://dx.doi.org/10.22201/iie.18703062e.1945.12.385

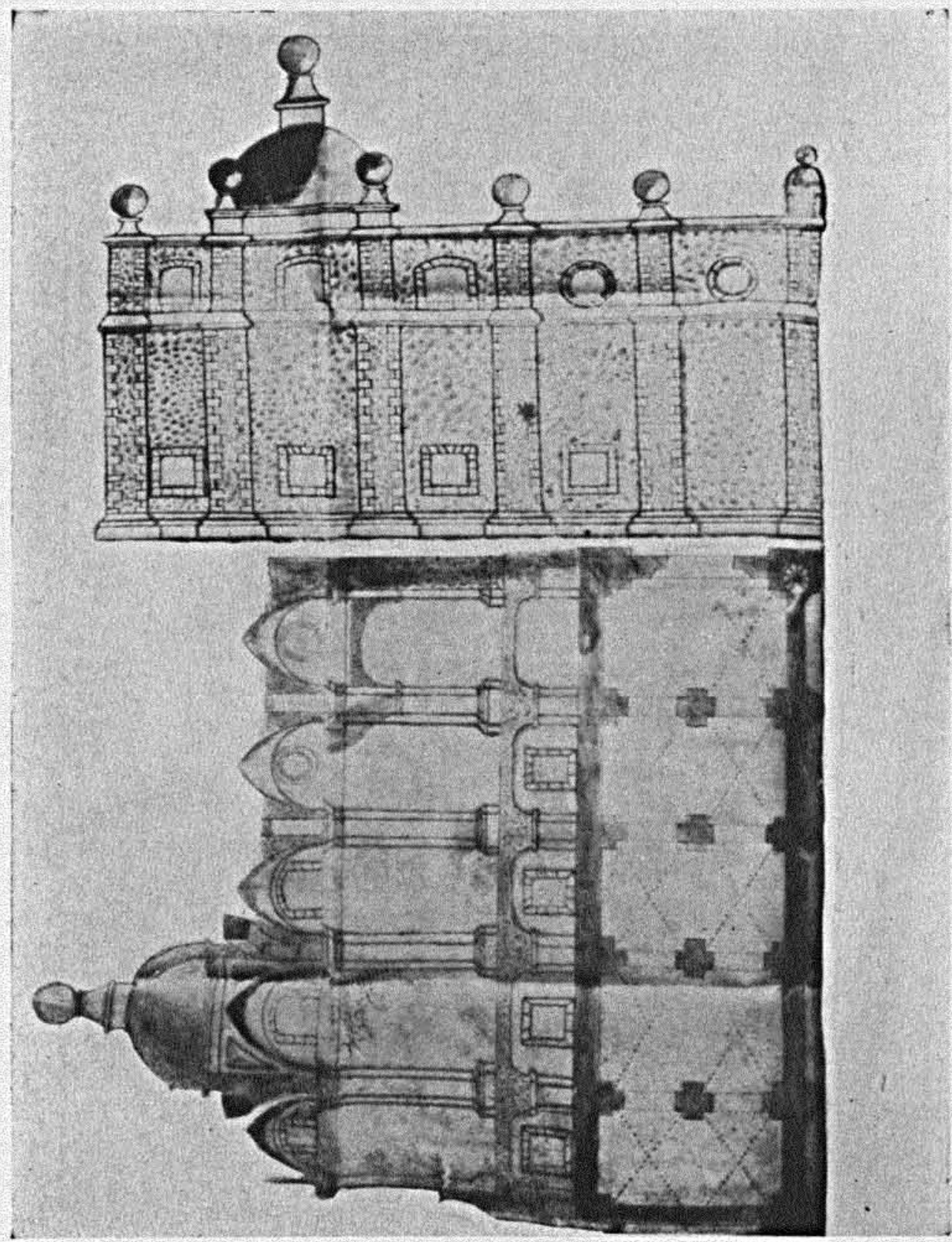

Fig. 2. Planta, corte y fachada lateral de la misma capilla. 
sias nesesarias para el asierto de una cosa de tanta ynportansia. VSS" proberán lo que más conbenga.-Diego de los Santos y Avila. (Rúbrica.)"

El gasto total fué calculado por Santos en 29,180 pesos, explicando que "he andado mui escaso en dicha tasasión $y$ se entiende que no entran los dichos materiales que oy tiene el edifisio biejo que se a de derribar".

El proyecto, como se ve, es minucioso y lleno de noticias interesantes para la historia técnica de la arquitectura colonial. Su preocupación mayor es que quede "mui fuerte" y que no haga vicio; es decir, que no sufra cuarteaduras y derrumbes, según la amarga experiencia que se tenia del peligroso subsuelo de México y de los temblores; pone th gran cuidado en la cimentación $\mathrm{y}$ en el cubrir las bóvedas contra las aguas y nos enseña algunos trucos como el de pintar a modo de cantería y de fingir los azulejos; recomienda mucho cuidado "al maestro que fabricare" la capilla siga sus instrucciones, pues según he dicho, era una mala costumbre colonial que un arquitecto hiciese los planos y otro la obra, y se muestra orgulloso de su portada, recomendando a su sucesor no se olvide un punto su dibujo, declarando con todo detalle los materiales que se han de usar en toda la fábrica.

La portada recuerda débilmente el renacimiento herreriano, pero ya con un incipiente barroco que rompe los frontones, tanto en el primer cuerpo como en el remate, y que prodiga los escudos. Las pilastras jónicas son almohadilladas, así como las jambas; el arco ostenta una elegante clave y las enjutas una piedra en punta de diamante. En el remate, también con pilastrillas almohadilladas, perdura un elemento herreriano, el de los perillones o estípites que enmarcan el escudo. Esta portada de Diego de los Santos está en perfecta consonancia con la arquitectura de la época, de lo cual pueden ser un ejemplo, por el momento, las fachadas de la iglesia de San José de Gracia, de 1660, y la linda portada del antiguo convento de San Francisco, de la entrada al coro, que hoy sólo se recuerda en el frontis del libro de Ramirez Aparicio: Los Conventos suprimidos en México.

Del arquitecto Diego de los Santos, además de sus labores como maestre mayor de la Inquisición, tengo las pocas siguientes noticias: en 1659 hace un largo peritaje del edificio de la Inquisición y de algunas casas pertenecientes al tribunal; ${ }^{\circ}$ en 1660 hace reparaciones al mismo edificio y va a Valladolid a opinar sobre el proyecto y planos de la catedral que había hecho su amigo y compañero Varrocio con otros arquitectos; en 1702 , con

5 Archivo General de la Nación. Ramo de Inquivición. Tomo 584, folio 87.

6 Archivo General de la Nación. Ramo de Inquisición. Tomo 1510, exp. 19. 
Felipe de Roa, Pedro de Arrieta y Marcos Antonio Sobrarías, firma un reconocimiento del Real Palacio, ${ }^{\top}$ y en 1712 hace el avalúo de las casas que dejó en herencia al contador Pedro Vidal de Fuentes en la calle "que va del convento de Santa Catarina de Sena a la puente de Leguizamo"."

Su vida fué, pues, muy larga, abarcando sus labores como arquitecto desde 1657, como primera fecha conocida, hasta 1712, cuya confrontación de firmas asi lo demuestra. Muchas obras deben haberse ejecutado por sus manos en cincuenta y cinco años de trabajo, que debemos exhumar de los archivos, no tan sólo como ésta de la capilla, que sólo quedó en proyecto, sino como "obras bibas" en piedra, según al dice, que quizás aún existen.

7 Ana María Lisño Pacheco. La Catedral de Morelia. En Arte en America y Filipinas, pág. 101. Archivo Genetal de la Nación. Ramo de Obras Públicas. Tomo 35, exp. 2. folio 126 .

8 Archivo General de la Nación. Ramo Templos y Conventos. Tomo 3. 